\title{
Characterization of gamma irradiation absorbing compounds from lichens for biomedical applications
}

\begin{abstract}
There is a significant public health concern about the potential effects of gamma radiation to human beings especially on reproductive outcomes. Disorders of reproduction to reproductive health have become prominent issues in recent past due to adverse effects of gamma radiation on reproductive functions in human beings subsequently leads to infertility. Lichens are the natural potential source which has the ability to absorb gamma radiation as they have radiation absorbing compounds in it. They are the combination of both fungal and algal partners which produces the cortical pigments to regulate the solar irradiance reaching the algal layer by absorbing the maximum light from sunlight and thus protecting the photosynthetic partner against intense radiation of sunlight. To keep in mind, attempts have been made to collect different lichen communities from Eastern Ghats of Tamil Nadu and subject to extract gamma radiation absorbing compounds from the thallus of lichens. The gamma radiation absorbing novel compounds have been separated, purified and characterized from lichens of Parmotrema, Parmelinella and Ramalina spp. By following the methods of TLC, HPLC, GC-MS and NMR. The results showed that gamma radiation absorbing compounds such as lecanoric acid, salacinic acid and atranorin were characterized. The proposed project would be of more useful to prepare new drug molecules from lichens against the adverse effect of gamma irradiations as chemotherapeutic agents.
\end{abstract}

Keywords: lichens, gamma radiations, irradiation effect, lecanoric acid, biomedical applications
Volume 3 Issue 4 - 2017

\author{
Ponmurugan P,' Ayyappadasan $\mathrm{G}^{2}$ \\ 'Department of Botany, Bharathiar University, India \\ ${ }^{2}$ Department of Biotechnology, K.S.R. College of Technology, \\ India
}

Correspondence: Ponmurugan P, Department of Botany, Bharathiar University, Coimbatore - 64I 046, Tamil Nadu, India, Email drponmurugan@gmail.com

Received: April 02, 2017 | Published: July 19, 2017
Abbreviations: HPLC, high-performance liquid chromatography; GC-MS, gas chromatography mass spectroscopy; C, carbon; $\mathrm{H}$, hydrogen; TLC, thin layer chromatography; RF, radio frequency

\section{Introduction}

As a potential health risk to human beings, ionizing radiation has been paid much attention recently. The studies on anti-radiation drugs are playing an important role to prevent radiation adverse effect. Ionizing radiation causes its adverse effects through the generation of oxidative stress that leads to massive destruction of various biomolecules. ${ }^{1}$ They are capable of inflicting deleterious effects on living cells by causing damages to cellular membranes and DNA. Membranes and DNA are the vital targets for radiation induced inactivation in the biological system. Exposure of living cells to ionizing radiation can produce directly chemical and biological modifications which alter the cellular functions as well. Also, indirectly it can generate Reactive Oxygen Species (ROS) from the radiolysis of water, which cause oxidative damage to DNA, proteins and lipids biosynthesis. ${ }^{2}$ According to the earlier report gamma radiation causes severe damage in the gastrointestinal tract, reproductive organs and bone marrow cells which lead to genetic diseases and disorders in human beings. ${ }^{3}$ In addition, cytoplasmic changes including swelling, vaculation, bursting and alteration of the various components in the plasma membrane and cytoskeleton were recorded due to reaction caused by gamma radiation.

In recentyears, several phytoceuticals and plant extracts with innumerable pharmacological properties have been reported to act as good radiation-protector due to the ability of scavenging the free radicals and modulating antioxidant defense system of the body by up/down regulation of the antioxidant gene expression. ${ }^{4}$ Medicines derived from plants have played a pivotal role in health care of ancient and modern cultures. The current estimate indicates that about $80 \%$ of people in developing countries still rely on traditional medicinal plantbased remedies to meet their primary healthcare. ${ }^{5}$ Some medicinal plants have been trialed for their anti-radiation property and many of them are found to be useful. ${ }^{6}$

Lichens are symbiotic organisms in which fungi (mycobionts) and algae (photobionts/phycobionts) are living together. Fungal partners are taking responsibility for the production of bioactive secondary metabolites which have a plenty of biomedical applications. ${ }^{7}$ Moreover, fungal partners are used for adherence role on both living and non-living substrata. On the other hand, algal partners are playing vital role in food synthesis which is being supplied to fungal partner for their growth and development. It has been recorded that lichens are known to live in regions where the UV radiation is particularly intensive because of the altitude and the ozone rarefaction. Lichen growth is abundance in higher altitude areas wherein low temperature along with least sunshine and high relative humidity along with high rainfall are recorded. ${ }^{8}$ In the Arctic and Antarctica regions where the ozone depletion is the highest, lichens represent a quantitatively important part of the photosynthetically active biomass. Over time, they have developed some protective tools that enable their survival under UV radiation. They synthesize pigments with antioxidant capacities and strong absorption in the UV region.

\section{Materials and methods}

For the purpose of the present study, samples of Parmotrema, Parmelinella and Ramalina spp lichens were collected from the 
Yercaud (Shevroy hills) and the Kolli hills belonging to Eastern Ghats of Tamil Nadu, India. The collected samples were identified by following the standard procedures from genus to species level. ${ }^{9}$ The characteristics of lichens including morphology and, anatomy, lichen acid existence, growth forms, powdery appearance of the thallus and the nature of fruiting bodies (ascoraps) embedded in the thallus were critically analyzed to identify lichen communities. Moreover, color spot tests have been performed upon applying the $\mathrm{KOH}$ and $\mathrm{Ca}(\mathrm{OH})_{2}$ on the thallus. The changing colors of the lichen thallus medulla treated with chemical reagents were recorded. ${ }^{10}$ Different lichens thallus types as listed above were irradiated in the irradiation chamber by gamma rays of low three doses between 1 and $5 \mathrm{~Gy}$ in the $1-7 \mathrm{~min}$. time interval. After radiation exposure, lichen thalli were subjected to cold extraction procedure with different solvents (petroleum ether, ethyl acetate, acetone, ethanol, methanol and water) preceded by preheating step. ${ }^{11}$ The specific lichen compounds that absorb gamma radiation were extracted. The samples were concentrated under reduced pressure in a rotary evaporator. The gamma radiation absorbing compounds were then purified by column chromatography ${ }^{12}$ followed by High-Performance Liquid Chromatography (HPLC) analysis (Agilent 1220, Boeblingen, Germany, C18, methanol: water: acetic acid ratio $=80: 20: 1)$ as described by Yoshimura $\mathrm{I}$ et al. ${ }^{13}$ The biochemical compounds identification in the purified fractions extract from the lichen were performed using Gas Chromatography-Mass Spectroscopy(GC-MS) analysis with the Perkin Elmer ${ }^{\circledR}$ Clarus 500 Gas Chromatograph (GC) - -- chemical library used NIST Version - Year 2005. Furthermore ${ }^{13} \mathrm{C}$ NMR and ${ }^{1} \mathrm{H}$ NMR spectra were recorded on $400 \mathrm{MHz}$ NMR spectrometer (Bruker) for quantitative spectroscopic analysis for carbon $(\mathrm{C})$ and hydrogen $(\mathrm{H})$ atoms in an organic compound to determine the nature and chemical formula of the compound. ${ }^{14}$

\section{Results and discussion}

The study of lichens diversity and distribution on the study site showed numerous biomedical potential due to the presence of lichen acids. Our previous report revealed that the selected lichen species such as Parmotrema, Parmelinella and Ramalina spp. were exhibited highest potential of antiradical hydrogen ions capacity of around 50$60 \%$ of inhibition. ${ }^{15,16}$ Hence, further investigation of above mentioned lichen species was carried out to measure the radio protectant activity by gamma radiation absorbing compounds. Lichen species were collected and authenticated from Yercaud and Kolli hills. Among the different solvents used in extraction process, as all the above mentioned, acetone was found to be most suitable in terms of getting the highest yield in extraction of gamma ray absorbing compounds from lichens. Compound development and solvent optimization in Thin Layer Chromatography (TLC) showed better separation in various Rf clause. TLC analysis were correlated with standard lichen sample of various Rf clause (Lecanoric acid - Rf3, Atranorin - Rf7 and Salazinic acid - Rf1). HPLC analysis indicated that retention times of lecanoric acid $\left(\mathrm{C}_{16} \mathrm{H}_{14} \mathrm{O}_{7}\right)$, salazinic acid $\left(\mathrm{C}_{18} \mathrm{H}_{12} \mathrm{O}_{10}\right)$ and atranorin $\left(\mathrm{C}_{19} \mathrm{H}_{18} \mathrm{O}_{8}\right)$ of different solvent extracts of various lichen species which was compared with standard lichen (Parmelinella wallichiana) of $13.11 \pm 0.1 \mathrm{~min}, 13.25 \pm 0.1 \mathrm{~min}$ and $16.92 \pm 0.6 \mathrm{~min}$ respectively. The spectroscopic analysis results revealed the presence of the lecanoric acid, salazinic acid and atranorin compounds (Figure 1-3). These compounds are having conjugated double $(=)$ bonds, three hydroxyl bonds $(-\mathrm{OH})$ with one carboxyl bond $(\mathrm{COOH})$ along with scavenging free radicals contained in it.

Studies on optimization of gamma radiation doses and exposing time intervals revealed that among the various doses, 1Gy was found to be optimum to stimulate the synthesis of gamma radiation absorbing compounds in the lichen thallus. The doses at 3Gy and 5Gy facilitated the senescence and found to be harmful to living cells in lichen thallus. Among the different time intervals tested, the exposure of lichens under gamma radiation at $3 \mathrm{~min}$ and $5 \mathrm{~min}$ were found to be optimum in terms of biosynthesis of compounds. Lichen fungi exposed to high light intensities are recognized to accumulate various pigments in the cortical layers overlying the algal cells. ${ }^{17}$ Lichens are having capacities to biosynthesis of various radiation absorbing molecules in the cortical region of the thallus. The radiation absorbing molecules are secondary compounds which are the combination of phenolics, alkaloids and terpenoids.
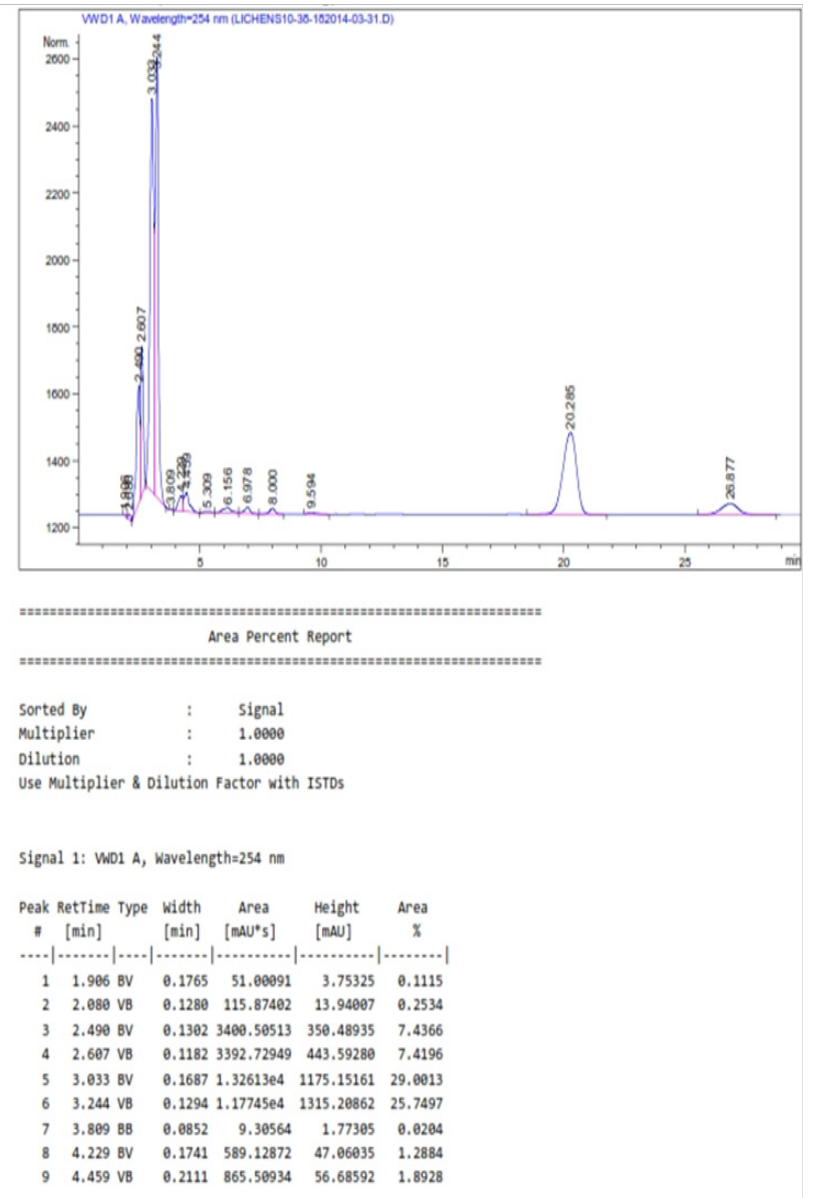

Figure I Characterization of gamma radiation absorbing compounds such as lecanoric acid, salacinic acid and atranorin from the acetone extract of lichen Parmotrema spp.

Consequently, several lichen metabolites such as calycin, rhizocarpic acid, usnic acid and mycosporine-like amino acids have demonstrated some photoprotective capacities. ${ }^{18}$ Solhaug KA et al. ${ }^{19}$ reported that lichens are good candidates for extracting radiations absorbing bioactive secondary metabolites. Some of the coloured lichen substances like parietin, usnic acid, melanins and calcium oxalate crystals are having capacities to absorb radiations. The coloured pigments mainly belong to the dibenzofurans, anthraquinones, xanthones (faintly yellow) and pulvinic acid derivatives ${ }^{20}$ and several orange coloured substances synthesized by lichens, such as chrysophanol, emodin, fallacinol and parietin or parietinic acid are having high potential enough to absorb radiations. ${ }^{21}$ To conclude the present study, Parmotrema, Parmelinella and Ramalina lichens are the potential candidates to extract gamma radiation absorbing compounds which has the plenty of scope in biomedical applications. 

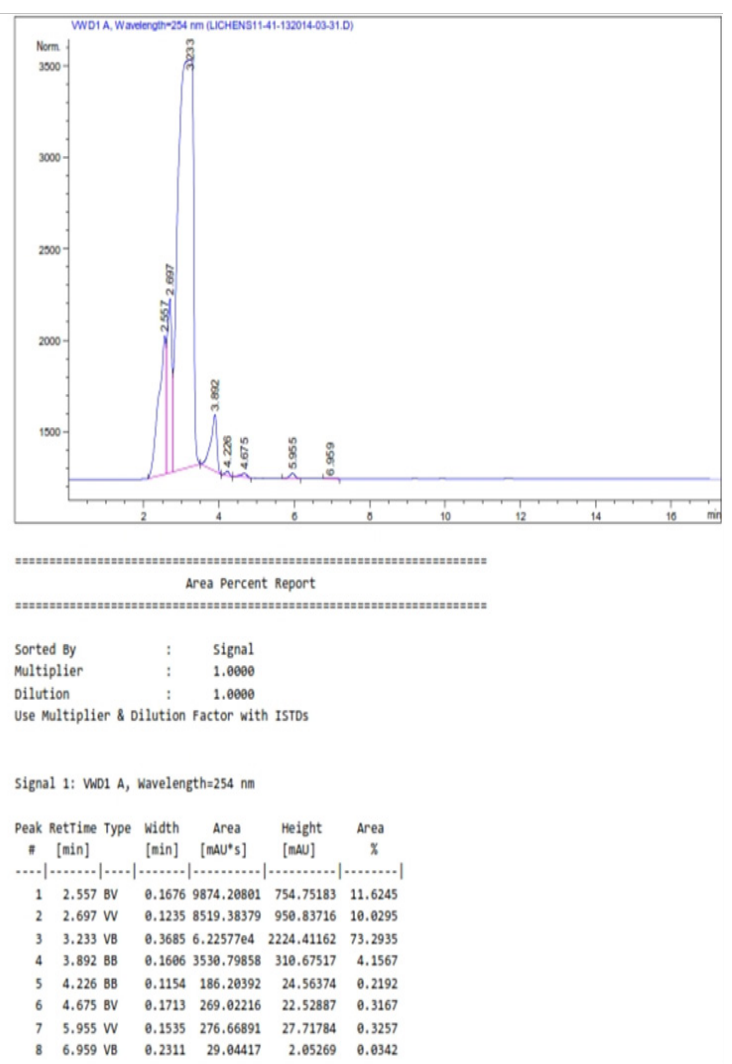

Figure 2 Characterization of gamma radiation absorbing compounds such as lecanoric acid, salacinic acid and atranorin from the acetone extract of lichen Parmelinella spp.

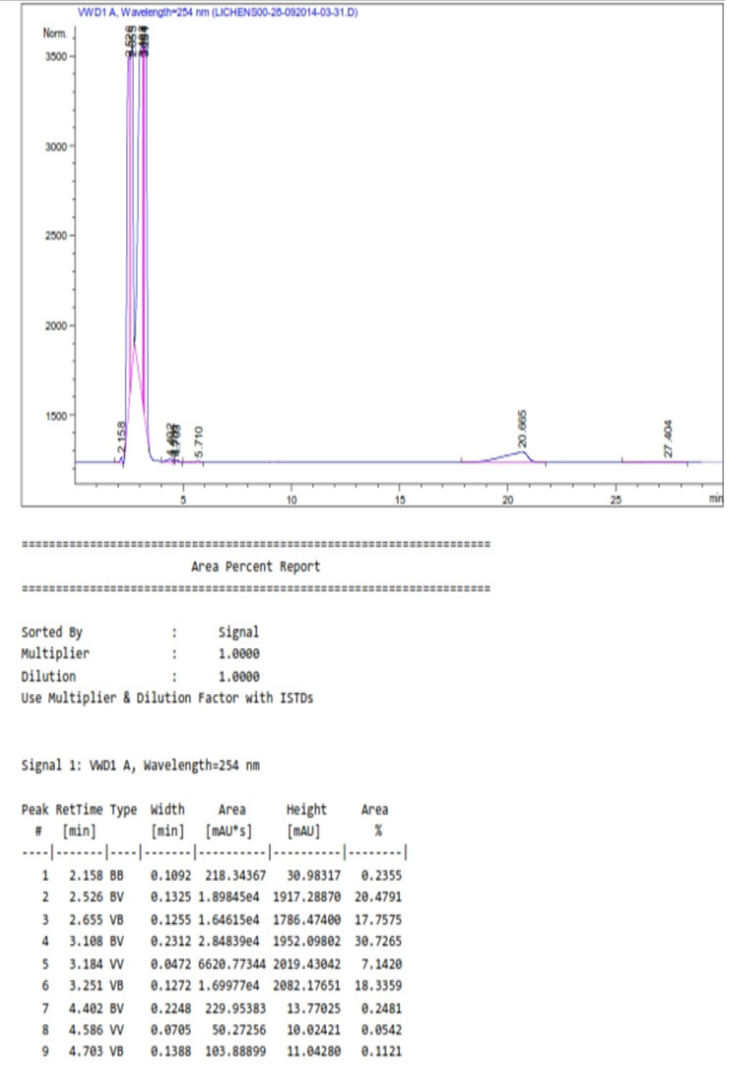

Figure 3 Characterization of gamma radiation absorbing compounds such as lecanoric acid, salacinic acid and atranorin from the acetone extract of lichen Ramalina spp.

\section{Conclusion}

Lichen species were clearly understood for various biological activities like antimicrobial, antioxidant, anticancer and etc., There is a limited utilization of active ingredients as drug molecule against particular disease. The present study concluded that selected lichen species possess radiation absorbing compounds in the order of Parmotrema $>$ Parmelinella $>$ Ramalina $s p p$. which helps to formulate radio protectant molecule. The lichen compounds such as lecanoric acid, atranorin and Salacinic acid might be responsible for the gamma radio protectant property. Further the above lichen compounds can be formulated and used for radiation absorbing activity.

\section{Acknowledgements}

None.

\section{Conflict of interest}

Author declares that there is no conflict of interest.

\section{References}

1. Sharma P, Parmar J, Sharma P, et al. Radiation-induced testicular injury and its amelioration by Tinospora cordifolia (An Indian Medicinal Plant) extract. Evidence-Based Complementary and Alternative Medicine. 2011;11:01-09.

2. Mansoura HH, Ismaelb NER, Hafez F Hafezc. Modulatory effect of Moringa oleifera against gamma-radiation-induced oxidative stress in rats. Biomedicine and Aging Pathology. 2014;4(3):265-272.

3. Nada AS, Hawas AM, Elmageed ZY, et al. Protective value of Aloe vera extract against g-irradiation induced some biochemical disorders in rats. J Rad Res Appl Sci. 2013;6:31-37.

4. Jagetia GC. Radioprotective potential of plants and herbs against the effects of ionizing radiation. J Clin Biochem Nutr. 2007;40(2):74-81.

5. Patwardhan B, Vaidya ADB, Chorghade M. Ayurveda and natural products drug discovery. Current Science. 2004;86(6):789-799.

6. Gehlot P, Soyal D, Goyal PK. Alterations in oxidative stress in testes of Swiss albino mice by Aloe vera leaf extract after gamma irradiation. Pharmacologyonline. 2007;1:359-370.

7. Ayyappadasan G, Madhu Preetha T, Ponmurugan P, et al. Antioxidant and antibacterial activity of Parmeliod lichens from Shevaroy hills of Eastern Ghats, India. Inter J Pharm Tech Res. 2015;8(9):13-23.

8. Ponmurugan P, Ayyappadasan G, Verma RS, Nayaka S (2016) Survey, distribution pattern and elemental composition of lichens in Yercaud hills of Eastern Ghats in southern India. Journal of Environmental Biology. 2016;37(3):407-412.

9. Ahmadjian V. The Lichen Symbiosis. New York: John Wiley \& Sons; 1993.

10. Awasthi DD. A Handbook of Lichens. In: Bishen Singh, editors. India; 2000 .

11. Sadasivam S, Manickam A. Biochemical Methods for Agricultural Sciences. New Delhi: Wiley Eastern Limited; 2006. 246p.

12. Sun Y, Zhou X, Liu J, et al. Streptomycesnanchangensis, a producer of the insecticidal, polyethane antbiotic nanchangmycin and antioarasitic macrolide meilingmycin, contains multiple polyketide gene clusters. $\mathrm{Mi}$ crobiology. 2002;148(2):361-371.

13. Yoshimura I, Kurokawa T, Kinoshita Y, et al. Lichen substances in cultured lichens. Hattori Bot Lab Res. 1994;76:249-261.

14. Hasliza Y, Husna A, Laily BD, et al. Chemical constituents of the lichens Cladonia multiformis and Cryptothecia spp. Malaysian Journal of Analytical Science. 2015;19(5):930-934. 
15. Upreti DK, Nayaka S. Lichenology in India (1996-2000). British Lichen Society Bulletin. 2000;87:66-67.

16. Nayaka S, Reddy MA, Ponmurugan P, et al. Eastern Ghats, biodiversity reserves with unexplored lichen wealth. Current Science. 2013;104(7):821-825.

17. Gauslaa Y, McEvoy M. Seasonal changes in solar radiation drive acclimatation of the sun-screening compound parietin in the lichen Xanthoria parietina. Basic Appl Ecol. 2005;6:75-82.

18. Roullier C, Chollet-Krugler M, Pferschy-Wenzig EM, et al. Characterization and identification of mycosporines-like compounds in cyanolichens, Isolation of mycosporine hydroxyglutamicol from Nephroma laevigatum. Ach Phytochemistry. 2011;72(11-12):1348-1357.
19. Solhaug KA, Gauslaa Y, Nybakken L, et al. UV-induction of sun-screening pigments in lichens. New Phytol. 2003;158(1):91-100.

20. Huneck S, Yoshimura I. Identification of lichen substances. Berlin, Germany: Springer; 1996. p. 1-493.

21. Johansson S, Søchting U, Elix JA, et al. Chemical variation in the lichen genus Letrouitia (Ascomycota, Letrouitiaceae). Mycological Progress. $2005 ; 4(2): 139-148$. 